\title{
Monumentalidade e hibridismo indo-português: discursos visuais talhados em pedra, madeira e marfim
}

\author{
Cibele E. V. Aldrovandi \\ Universidade de São Paulo
}

\begin{abstract}
RESUMO: ESTE ARTIGO ANALISA ALGUNS ASPECTOS DO HIBRIDISMO INDO-PORTUGUÊS PRESENTES NA ARTE E NA ARQUITETURA SAGRADA E SECULAR, SOB A ÓTICA DE UM DISCURSO MONUMENTAL HEGEMÔNICO ENGENDRADO PELO COLONIALISMO PORTUGUÊS EM TERRITÓRIO INDIANO.
\end{abstract}

ABSTRACT: THIS ARTICLE ANALYSES CERTAIN ASPECTS OF INDO-PORTUGUESE HYBRIDISM TO BE FOUND IN ART AND ARCHITECTURE, BOTH SACRED AND SECULAR, AND ARGUES THAT THEY REFLECT A HEGEMONIC DISCOURSE CONCERNING THE MONUMENTAL ENGENDERED BY PORTUGUESE COLONIALISM IN INDIA.

PALAVRAS-CHAVE: MONUMENTALIDADE, HIBRIDISMO, INTERDISCURSIVIDADE, PORTUGAL, ÍNDIA

KEY-WORDS: MONUMENTALITY, HYBRIDISM, INTERDISCURSIVITY, PORTUGAL, INDIA 
Deus por certo vos traz, porque pretende

Algum serviço seu por vós obrado;

Por isso só vos guia e vos defende

Dos inimigos, do mar, do vento irado.

Sabei que estais na Índia, onde se estende

Diverso povo, rico e prosperado

De ouro luzente e fina pedraria,

Cheiro suave, ardente especiaria.

(CAMÕES, Os Lusiadas, VII. 31)

arte moderna e contemporânea produzida em Goa aparece frequentemente permeada pela religiosidade e constitui um campo extremamente fértil para o estudo do hibridismo latente que essa região do subcontinente indiano presenciou ao longo dos séculos. A obra intitulada Cristo, de Francis Newton Souza (Fig. 1), datada de 1948, fornece elementos sobre essa interação cultural e a multiplicidade de referências visuais que compõe o repertório desse importante artista goês. Nessa pintura, as pinceladas e as cores intensas, marcadas por referências expressionistas, abstracionistas e cubistas, permitem entrever sincronicamente um antigo ícone bizantino de Jesus, apropriado da herança cristã portuguesa e reinserido na gramática expressiva da arte moderna indiana (KURTHA, 2006, p. 37). Souza e outros artistas indianos fundaram o Progressive Artists Group (PAG) em Mumbai na época da independência da Índia (1947). O manifesto daquele grupo rejeitava a tradição artística acadêmica, valorizando a própria herança cultural conjugada às tendências do modernismo europeu. Se, por um lado, Souza possui "uma qualidade religiosa em seu trabalho que é medieval em sua simplicidade e em sua singela sensação de arrebatamento" (MULLINS, 1962, p. 40), por outro, sua obra singular incorporou e, ao mesmo tempo, desafiou muitas das noções estéticas e percepções estereotipadas sobre a religião e a cultura goesas.

Com vistas a compreender alguns aspectos do hibridismo indo-português, este artigo busca discutir esse período, observando-o sob a ótica de um discurso monumental promovido no campo das artes e da arquitetura - tendo a Goa antiga como seu principal centro de produção, durante os séculos XVI e XVII -, e vai inseri-lo em uma perspectiva interpretativa diacrônica do colonialismo e dos processos de mudança cultural ali encontrados. 


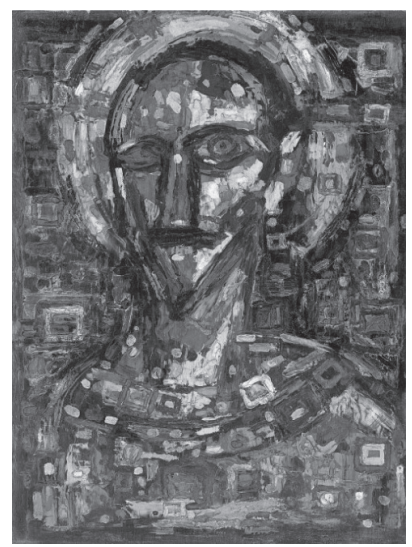

Figura 1 Cabeça de Cristo. Francis Newton Souza. Óleo sobre cartão, 1948. Coleção particular do artista (Fonte: KURTHA, 2006).

A presença portuguesa na Índia, como observado por grande parte dos historiadores, teve dois principais mecanismos propulsores: o comércio e a conversão das almas. Na época em que os portugueses aportaram no subcontinente, o mapa geopolítico da região estava dividido entre um grande número de reinos hindus - majoritariamente na porção setentrional - e de sultanatos muçulmanos - no centro e norte do país. A partir das recém-inauguradas rotas entre a Europa e as Índias orientais, o objetivo português era tomar pela força das armas o controle do monopólio comercial marítimo venezianomuçulmano de então (SUBRAHMANYAM, 1997, p. 128-29; BOXER, 2002, p. 52, 56-7). Os portugueses puderam contar com um século inteiro para se firmar na costa indiana, antes da chegada de outros colonizadores europeus. A presença exclusivamente portuguesa na Índia se estendeu até o início do século XVII, quando os ingleses criaram a Companhia das Índias Orientais, para concorrer com o monopólio comercial português no mercado europeu. Em seguida, vieram os holandeses (1602), os franceses (1664) e, finalmente, os dinamarqueses (1675).

Os remanescentes materiais da ocupação portuguesa, iniciada no século XVI, ainda permanecem impressos na paisagem litorânea indiana contemporânea na forma de fortalezas, igrejas e edifícios. Alguns desses sítios estão mais bem conservados, caso de Goa, cuja história se estendeu por 450 anos, antes da reintegração pelo governo indiano em 1961. Outros enclaves portugueses e 
suas fortalezas pontilharam a costa oeste da Índia, como Diu e Damão, no atual Gujarate; e Baçaim, Bombaim e Chaul, em Maharashtra, todas províncias ao norte de Goa e, ainda, ao sul, Cananore, Calicute e Cochin, em Kerala.

Construídos sob a égide portuguesa e, em muitos casos, sobre povoações preexistentes, esses portos fortificados cumpriam a função de bases navais e entrepostos comerciais, viabilizando a comunicação ao longo da rota marítima. Esses centros de administração colonial eram cidades com traçado urbano planejado (TEIXEIRA, 1996, p. 23), cujo hibridismo arquitetônico é observado em uma mescla de fortificação militar e construções eclesiásticas de origem europeia erigidas em meio à paisagem e sociedade indianas preexistentes (Fig. 2). Em meio às batalhas pela tomada desses territórios, o subjugo português de Goa ocorreu durante o governo de Afonso de Albuquerque (1509-15), no dia de Santa Catarina, em 10 de novembro de 1510.

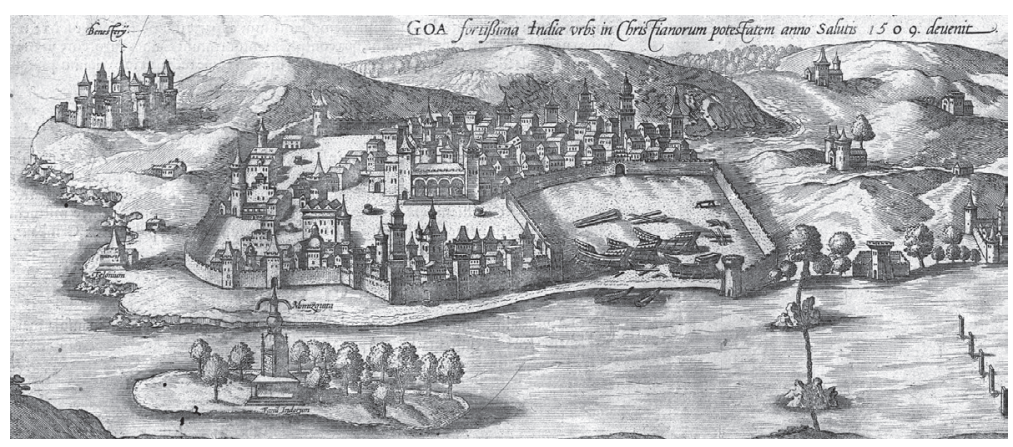

FIgURA 2 Detalhe de gravura em metal com vista da cidade fortificada de Goa e da monumentalidade dos edifícios (Fonte: BRAUN, Civitates Orbis Terrarum I. 57, 1572).

As evidências arqueológicas mais antigas sobre a presença de dinastias regionais nesse território foram confirmadas pela presença de discos de cobre datados do período Maurya, remontando ao século III a.C. Mais tarde, a região aparece descrita como um estado semiautônomo chamado Kadamba, durante o império Chalukya, que se estendeu entre 1000 e 1300 d.C. e foi incorporada pelo império Vijayanagar, na metade do século XIV. Assim, a política regional preexistente alternava o domínio de governantes locais com a subordinação aos impérios indianos que ali se sucederam. Um deles, o império Bahmani, tomou 
o controle da região em 1490 e o sultão Yusuf Adil Khan, de Bijapur, passou a governar Goa até o advento português (AXELROD e FUERCH, 1998, p. 449). A história portuguesa revela que, rapidamente, Albuquerque transformou-a no quartel-general e principal porto comercial da costa oeste (BOXER, 2002, p. 61; SUBRAHMANYAM, 2007, p. 1372).

Antes e depois da chegada dos portugueses, as terras em Goa estiveram sob o controle de duas castas dominantes, os brâmanes Gaud Sarasvat e os marathas, de origem kshatriya, a casta guerreira (chamados Chardós pelos portugueses). A antiga Gomantak, como Goa é conhecida nas fontes hindus, é descrita no Sabyadri Khanda do Skhanda Purana, como uma terra bela e verdejante, protegida por Parasurama - o sexto avatar de Visnu (DA CUNHA, 1972, apud. AXELROD e FUERCH, 1996, p. 402) e se inscreve de forma praticamente perfeita na distribuição geográfica das 31 vilas do antigo território da conquista portuguesa (BADEN-POWELL, 1900 p. 266), o que aponta para uma convergência dos indícios arqueológicos e das fontes históricas sobre os diferentes grupos que formaram a sociedade e cultura goesas.

No século XIX, Da Cunha (1876) visitou e descreveu de modo pormenorizado outro desses imponentes marcos do poderio ultramarino português: as ruínas de Agar Kot, a Fortaleza portuguesa de Chaul - a antiga Simylla do Périplo do Mar Eritreu (GOGTE e ALDROVANDI, 2006). Embora permeadas de um ponto de vista etnocêntrico, suas memórias exprimem com vivacidade aquela paisagem arruinada e permitem traçar a monumentalidade da empreitada militar, econômica e evangelizadora portuguesa, cuja dimensão material é revelada pelas muralhas de pedra (Fig. 3) que cercavam essa cidade e pelos edifícios religiosos abrigados em seu interior, como a antiga catedral (Fig. 4).

A arquitetura monumental foi geralmente definida por exceder, em escala e elaboração, os requisitos de suas funções práticas simbolizando a habilidade e a força daqueles que detinham o poder (TRIGGER, 1990, p. 120), de modos não tão obviamente coercivos (LEFÉBVRE, 1991, p. 143). As cidades ultramarinas procuravam, desde o princípio, espelhar a estrutura e a fortuna do império (TEIXEIRA, 1996, p. 26). Nesse sentido, a materialização do poder político e religioso português permaneceu legível na paisagem indiana sob a forma de sobreposições na monumentalidade: a própria planta da cidade, as portas e as muralhas das fortalezas, os edifícios sagrados e cívicos evidenciam essa morfogênese. Materialmente, é possível dizer que o caráter fronteiriço e 
autônomo (ANDRADE, 1999, p. 36) dos enclaves portugueses em território indiano encerram discursos monumentais dirigidos aos diferentes estratos da sociedade que ali se desenvolveu.

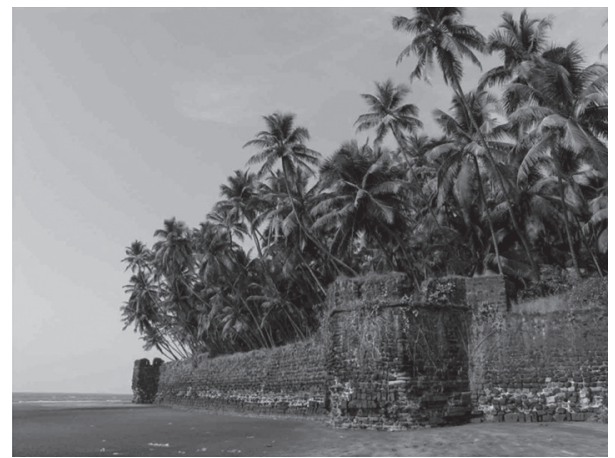

Figura 3 Bastiões e muralhas a sudoeste da fortaleza portuguesa de Chaul, atualmente tomada pela plantação de coqueiros (Fonte: ALDROVANDI, 2005).

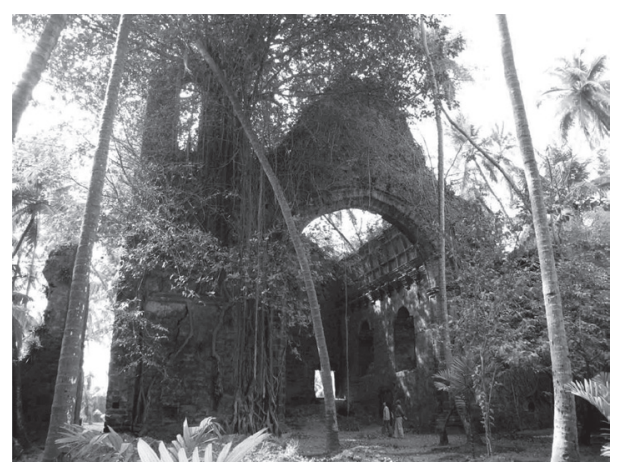

Figura 4 A antiga Catedral de Chaul-Igreja Matriz de Nossa Senhora do Mar, erigida em 1534, pelo frei franciscano Antonio do Porto, hoje tomada pelas raízes de grandes árvores. A nave da igreja mede c. $30 \mathrm{~m}$ por $10 \mathrm{~m}$ e as paredes, $9 \mathrm{~m}$ de altura (Fonte: ALDROVANDI, 2005).

Os portugueses haviam chegado à Índia a procura de cristãos. A tradição atribui a chegada de São Tomás - o Apóstolo Tomé - em 52 d.C., a Kodungallur, onde teria fundado a Igreja Síria do Malabar e iniciado a conversão de famílias judias e brâmanes proeminentes. Fontes escritas narram que Vasco 
da Gama e sua tripulação, ao chegar a Calicute no século XVI, visitaram templos hindus que pensavam ser igrejas cristãs e, em alguns casos, teriam confundido as imagens de divindades hindus, ali consagradas com as de Nossa Senhora (SUBRAHMANYAM, 1997, p. 133-34).

A cunhagem dos primeiros exemplares do Escudo de São Tomé (Fig. 5) com o ouro provindo da Índia ocorreu em Lisboa no ano de 1544. Por volta de 1548, a Casa da Moeda de Goa também passou a emitir o São Tomé, que se manteve por muito tempo em circulação (BOXER, 2002, p. 73). O uso da imagem do Apóstolo Tomé na numismática indo-portuguesa conjuga alguns referenciais importantes à compreensão do discurso colonial português. $\mathrm{Na}$ representação, o santo segura o esquadro, atributo que o fez padroeiro dos arquitetos e pedreiros, que refletia diretamente os ideais civilizadores ultramarinos portugueses, como vimos, materializados de modo monumental nas cidades-fortaleza da costa oeste indiana.
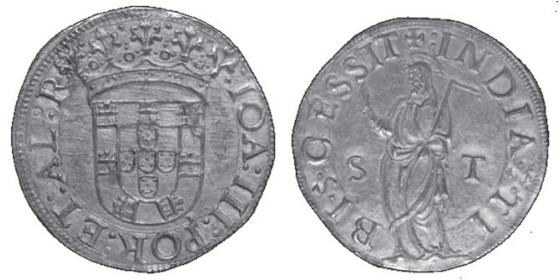

Figura 5 Escudo de São Tomé de 1544/45. Período colonial indo-português, ouro, 32 mm. Cunhado em Lisboa durante o reinado de D. João III (1521-1557). No anverso, o escudo real coroado e a inscrição: João III Rei de Portugal e dos Algarves. No reverso, a imagem de São Tomé, de pé e corpo inteiro, portando o esquadro e em atitude de pregação, ladeada pelas letras $\mathrm{S}$ e T, na inscrição:

S. Tomé a Índia foi-te consagrada (Fonte: SALGADO, 2009).

Além disso, a imagem do santo arquiteto - o primeiro cristão a chegar à Índia - lavrada em ouro e, portanto, imbuída de alto valor material, nos esclarece, ao mesmo tempo, sobre a dimensão das intenções portuguesas de aproximação com os cristãos locais. A fontes históricas mencionam que, durante o Sínodo Diocesano de Diamper - que teve por objetivo promover a romanização a Igreja de São Tomás, colocando-a sob a égide da Igreja Católica, ocorrido no Malabar no ano de 1599, sob os auspícios de Aleixo de 
Menezes, arcebispo de Goa -, estiveram representadas mais de 100 Igrejas, o que comprova uma forte presença cristã anterior à chegada dos europeus à Índia. Inicialmente, as relações entre os cristãos do Malabar e os católicos portugueses foi amistosa, mas, com o passar do tempo e, mais precisamente, na chegada da Companhia de Jesus, esse panorama modificou-se, e houve a cisão dessa antiga Igreja indiana (BROWN, 1982).

Antes da chegada dos jesuítas, com novos homens e novos métodos de conversão, os missionários não haviam empreendido um esforço efetivo para aprender as línguas locais e a dependência de intérpretes certamente prejudicava a transmissão de argumentos teológicos complexos aos possíveis conversos (BOXER, 2002, p. 80-81). As narrativas mencionam a combinação de métodos de persuasão e força próprios da Inquisição na conversão dos nativos. Em Goa, a partir de 1540, um grande número de templos hindus foi destruído e leis opressivas foram promulgadas, prevendo a expulsão de professores e homens santos das demais religiões, o confisco e destruição de livros religiosos, a proibição de cerimônias públicas e de procissões sob pena de encarceramento, com a intenção de banir a prática das religiões locais em território português. Muitos sítios que possuíam templos ou mesquitas foram reocupados por igrejas e conventos, que passaram a receber os lucros provenientes das terras ao seu redor. Entretanto, o cumprimento dessas leis variou em cada região e, na esfera social, a proibição de convívio entre cristãos e não cristãos não parece ter surtido o efeito desejado, pois muitos supostos convertidos continuaram a praticar rituais hindus (AXELROD e FUERCH, 1996, p. 409-12; BOXER, 2002, p. 82-9).

Inserida nesse contexto é que surge a chamada arte e arquitetura indo-portuguesas, uma produção artística desenvolvida entre os séculos XVI e XVIII. Ela teria sido produzida majoritariamente em Goa (esp. entre XVII e XVIII), embora ainda existam dificuldades para se determinar com segurança o local original de manufatura e a cronologia precisa de grande parte das peças. $\mathrm{O}$ termo indo-português apresenta definições distintas (IRWIN, 1955; TÁVVORA, 1983), mas aqui será conceituado como a arte produzida na Índia e adaptada à cultura cristã ocidental, por artífices nativos - convertidos ou não ao cristianismo -, nos territórios sob domínio português e cuja produção esteve orientada tanto para a demanda crescente dessa população no próprio subcontinente quanto para a exportação. Os artífices hindus e cristãos converti- 
dos copiavam os modelos europeus e, gradualmente, passaram a incorporar elementos formais - hindus, budistas e islâmicos - criando uma arte híbrida.

Nesse sentido, ao servir como uma mídia poderosa para a instrução popular sobre os mistérios da fé, a arte indo-portuguesa fornece indícios importantes para a reconstrução histórica e social daquele período. $\mathrm{O}$ uso da iconografia como veículo da catequese era um caminho certamente facilitador para disseminação da doutrina cristã. Propaganda e estratégias de persuasão religiosa semelhantes, pautadas pelo uso da imagética, já haviam sido utilizadas pelo budismo com grande eficiência havia pelo menos um milênio e meio no subcontinente indiano - como aquela observada na arte de Gandhâra (ALDROVANDI E HIRATA, 2005).

No início do século XVI, quando Albuquerque chegou a Goa, a presença e a intensidade das artes hindu e muçulmana eram muito visíveis, materializando a força das culturas da civilização preexistente. Os testemunhos que corroboram a impressão dos portugueses sobre a expressão arquitetônica e artística dos templos hindus indicam um contexto competitivo, no qual "a eficácia da ação evangelizadora tornava imperativa a construção e ornamentação das igrejas católicas com uma suntuosidade não inferior à dos templos hindus e das mesquitas muçulmanas" (REGO, 1949, p. 503, apud. EUSÉBIO, 2003, p. 106) que fossem, por sua vez, "capazes de competirem com o esplendor artístico que os portugueses encontraram na Índia, particularmente em Goa" (EUSÉBIO, 2003, p. 105, 110). Nesse sentido, a monumentalização das igrejas e da talha sacra em seus interiores eram uma resposta direta ao caráter exuberante da arte e arquitetura encontradas no milieu indiano. Algo invariavelmente viabilizado pelo uso de artífices locais, exímios herdeiros da tradição milenar da escultura em madeira e em marfim.

Embora, em teoria, se esperasse que os artífices fossem cristãos convertidos, na prática, o predomínio dos artistas hindus em Goa é amplamente reconhecido. $\mathrm{Na}$ Índia "a Igreja viu-se na contingência de se adaptar ao contexto local (...) aceitando, ou, pelo menos, tolerando o hibridismo artístico daí resultante, (...) uma miscigenação artística, uma fusão dos léxicos europeu e oriental" (EUSÉBIO, 2003, p. 109-10). Com o passar do tempo, houve um distanciamento dos modelos europeus, acompanhado de um aumento de traços autóctones e a inserção de motivos tipicamente indianos, por vezes paradoxais, como os nâga e as nâgin - divindades-serpente aquáticas associadas 
à fertilidade e extremamente populares em todo o subcontinente, possivelmente associadas a cultos pré-védicos - e que na gramática indo-portuguesa aparecem geralmente representadas frontalmente, em pé e com as caudas bifurcadas e entrelaçadas. Assim, mecanismos como a intericonicidade e o hibridismo presentes na arte indo-portuguesa foram capazes de criar diálogos iconográficos distintos dos originais e favorecer configurações interdiscursivas entre entidades amplas e heterogêneas (FOUCAULT, 1969, p. 35, 178; ALDROVANDI, 2009, p. 58).

A conversão dos gentios previa também a "oferenda, por parte dos missionários, de pequenas peças simbólicas que lhes materializavam a nova doutrina e lhes incutiam a Fé" (EUSÉBIO, 2003, p. 105). Assim, na imaginária desenvolveu-se uma grande diversidade de soluções formais, presentes nas pequenas imagens devocionais, nos presépios, nos oratórios e nos "Calvários de Pousar". Entretanto, é nas imagens do Bom Pastor que ficaram mais bem caracterizados os mecanismos discursivos a operar na imagética indoportuguesa. Essa iconografia singular desenvolveu-se, na maioria dos casos, sobre um suporte tipicamente local - o marfim, com ou sem policromia e douramento. Apesar da originalidade e complexidade, a produção dessa representação esteve restrita ao século XVII (TÁVORA, 1983, p. XLVII).

Por questões de espaço, aqui serão apresentados e discutidos apenas os principais elementos que fornecem indícios do hibridismo e da monumentalidade discursiva que essa iconografia encerra. Uma descrição minuciosa desse repertório iconográfico pode ser encontrada em Távora (1983), um dos pioneiros a pesquisar essa representação de maneira sistemática.

O esquema iconográfico do Bom Pastor indo-português (Fig. 6) tem como figura central o Menino Jesus, que aparece quase sempre sentado, pensativo ou adormecido (os olhos cerrados ou semicerrados), com uma ou duas ovelhas no colo, sobre o ombro, ou nas laterais. As pernas do menino estão geralmente cruzadas na altura dos tornozelos, em uma variação do pralambapâdâsana - a postura europeia - encontrada na iconografia budista desde o século I d.C.

Na iconografia paleocristã o Bom Pastor está em pé e carrega uma ovelha sobre os ombros - cuja origem é geralmente atribuída às imagens de Hermes Kriophóros [Pausanias, IV, 33] -, já na Índia, essa representação desenvolve uma complexidade iconográfica distinta e extremamente elaborada. Interes- 
sante notar que o deus Mithra, dos romanos, que devido à origem comum indo-europeia também figura no panteão persa e védico-bramânico, desde o segundo milênio a.C., era chamado de "bom pastor" (ROBERTSON, 1911, p. 332), trata-se de uma representação facilmente assimilável por sociedades distintas, uma vez que se insere em um meio pré-agrário, pastoril.

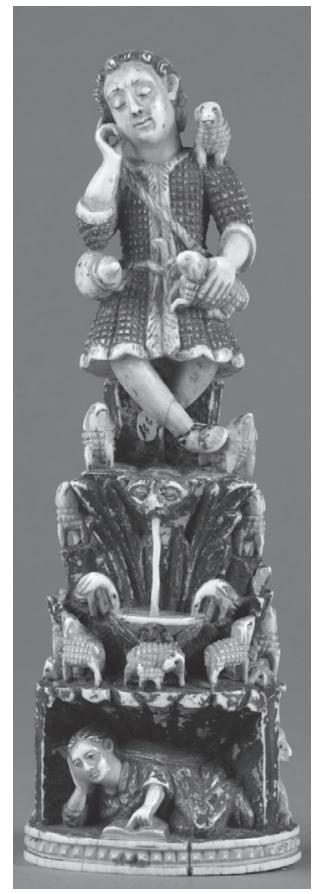

Figura 6 Bom Pastor. Marfim com vestígios de policromia e douramento.

Goa, século XVII (c. 1650), c. 18 cm (Fonte: CVictoria and Albert Museum, Londres).

A substituição do Cristo adulto por um menino é a primeira modificação importante dessa representação na arte indo-portuguesa (TÁVORA, 1983, p. XLVIII), atribuída ao "crescente interesse pela infância divina e profana e de desenvolvimento do culto a Cristo Menino" (EUSÉBIO, 2005, p. 26). Távora, entretanto, inicialmente descarta a possibilidade da origem e do significado dessa representação indo-portuguesa do Menino Jesus estarem associados a elementos ou à iconografia hindu ou budista, preferindo recorrer a um suposto protótipo europeu desconhecido. No entanto, logo após 
essa afirmação, o próprio estudioso reconhece a presença de elementos de origem budista ("greco-búdica", como prefere), como, por exemplo: o estilo do cabelo, a postura sentada, a posição do braço e da mão direita, os olhos semicerrados, "a expressão calma e o sorriso hermético de concentração expectante são extraídos das representações orientais da 'Primeira Meditação' do Buda" (TÁVORA, 1983, p. 85). A arte de Gandhâra, citada pelo estudioso, forneceu um extenso repertório imagético sobre a narrativa biográfica do Buda Sâkyamuni, que inclui vários episódios de sua infância e juventude, algo que pode ter influenciado a arte indo-portuguesa e a recorrência das imagens do Menino Jesus, uma vez que já havia um repertório formal preexistente e conhecido dos escultores locais. Curiosamente, após negar a influência do contexto indiano, o mesmo estudioso menciona a aposição, na base de uma das imagens discutidas, de uma representação de Krsna Gopâla, em seu aspecto pastor - cabe lembrar, uma das mais populares do hinduísmo -, que em suas palavras "permite constatar a identificação do Bom Pastor com esta divindade: ambos pertencem a Trindades, ambos encarnaram para salvação da Humanidade, ambos foram divinos pastores de gado" (TÁVORA, 1983, p. 86). As aparentes contradições presentes nas descrições apresentadas pelo estudioso, especialmente no tocante à influência hindu e budista sobre essa iconografia, mereceriam ser revistas, num momento oportuno, sob a luz das abordagens críticas do pós-colonialismo (SANTOS, 2002).

Um outro elemento formal, entretanto, nos chama mais a atenção. O Bom Pastor indo-português aparece sentado sobre uma peanha, cujo aspecto formal mais recorrente é a de um monte rochoso. Na porção frontal e nas laterais dessa montanha, em degraus, encontra-se distribuída uma série de elementos iconográficos de complexidade variada. Como observado acertadamente, a montanha rochosa sobre a qual a imagem se senta estaria associada à montanha sagrada - a morada dos deuses no hinduísmo (TÁVORA, 1983, p. 88). Ora, o Monte Meru, no hinduísmo, no budismo e no jainismo, é o centro dessas cosmologias - o axis mundi - materializadas na arquitetura religiosa em templos e estupas. Na iconografia indo-portuguesa do Bom Pastor, a presença da montanha realizada em degraus nos remete aos templos hindus, cujos vimana ou sikhara (torres) que se erguem sobre o garbhagrha (sanctum sanctorum) - eles mesmos construídos em degraus sucessivos -, são a representação simbólica da montanha sagrada na arquitetura religiosa hindu. 
É possível, portanto, pensar que estamos novamente diante de um caso de monumentalidade, concebida simbolicamente em forma de peanha-micro/ macrocosmo e que, nesse caso - apesar de executada em um volume constrito pela própria materialidade do suporte em marfim -, também encerra uma interdiscursividade visual de caráter monumental.

Alguns exemplares da imagem do Bom Pastor possuem um elemento em forma de árvore que se ergue na porção posterior da escultura e também pode apresentar proporções monumentais (TÁVORA, 1983, p. 83-93). A árvore também pode ser associada à cosmogonia das religiões indianas como, por exemplo, a árvore Bodhi que na iconografia budista aparece atrás do assento do Buda e está diretamente associada à sua Iluminação. Interessante também destacar a presença recorrente de Santa Maria Madalena penitente nessas representações do Bom Pastor, que aparece representada no degrau inferior da montanha, deitada ou sentada à maneira indiana em uma gruta. Sua biografia encontra um possível paralelo no budismo, na cortesã de Vaisâlî, de nome Amrapâli, convertida após o encontro com o Buda.

As plantas, do mesmo modo, são geralmente da flora local, mas também possuem simbologia específica. A flor de lótus está associada à pureza e figura como assento dos deuses hindus, bem como dos Budas e Bodhisattvas. A árvore asoka, típica dos Gates ocidentais indianos, está associada ao culto aos yaksa e yaksî - divindades pré-védicas que habitam as árvores e estão ligadas à fertilidade -, no budismo, a rainha Mâyâdevî teria dado a luz ao futuro Buda Sâkyamuni sob uma dessas árvores; e, no hinduísmo, ela está associada a Kâmadeva, deus do amor e do desejo, sendo essa flor, uma de suas setas. Os pûrnaghata, vasos da abundância, presentes na iconografia hindu e budista, também aparecem na iconografia do Bom Pastor.

Dessa maneira, é possível pensar a gênese da arte indo-portuguesa como um mecanismo discursivo capaz de congregar elementos visuais polissêmicos a recursos mnemônicos de origens diversas que favoreciam o discurso religioso colonial para uma população majoritariamente iletrada. A religião e o ritual são reconhecidamente capazes de reduzir conflitos políticos e, em muitos casos, o aumento na escala da produção simbólica está direta e proporcionalmente associado às pressões sociopolíticas presentes em uma sociedade (HODDER, 1982). Algo que os colonizadores portugueses certamente experimentaram nos anos de seu domínio em território indiano. Daí, a neces- 
sidade da criação de uma retórica iconográfica conciliatória capaz de acessar os diferentes grupos sociais que coabitavam na região, buscando convertê-los à nova fé.

No entanto, se por um lado houve uma apropriação mútua "dos receituários artísticos português e indiano, promovendo a emergência de novas sintaxes formais e figurativas" (EUSÉBIO, 2003, p.111), por outro, o hibridismo religioso presente na imagética cristã indo-portuguesa que, a princípio, pode parecer um indício do sucesso da empreitada colonial em Goa, foi, mais recentemente, analisado sob a ótica de uma resistência hindu que - uma vez reinserida em uma perspectiva diacrônica de longa duração -, resistiu até mesmo às brutalidades da Inquisição e sobreviveu a mais de 450 anos de dominação. Essa resistência é observada internamente no hibridismo goês; mas também, na conjugação da diáspora hindu em direção à "terra dos mouros" (i.e. sob controle do império Bijapur) com a formação de um cinturão de templos erigidos além das fronteiras da região sob domínio português para abrigar a divindades hindus retiradas de Goa (AXELROD e FUERCH, 1996, p. 388-92, 419-20, 439-41).

Nesse sentido, trata-se de uma história de muitas vias e não de mão única, como muitas vezes ela foi escrita. Em Goa, como vimos, a história dos predecessores dos portugueses antecede em pelo menos 1500 anos o seu advento. Interessante, nesse caso, é que a diacronia extensa do colonialismo português resultou em um anacronismo duplo: por anteceder e ter continuado a existir depois do colonialismo hegemônico das grandes potências (SANTOS, 2002, p. 11), o que produziu uma luta entre colonizadores e colonizados bastante distinta daquela observada em outras partes do sul da Ásia.

Nesse sentido, é possível dizer que o poderio português travou uma batalha importante pela hegemonia em Goa, por meio de símbolos produzidos no campo das artes e da arquitetura religiosa e secular. As antigas fortalezas e edifícios religiosos, a talha sacra do interior das igrejas e a simbologia do Bom Pastor encerram discursos monumentais e híbridos. Tais práticas foram engendradas pelo poder colonial português para subjugar as populações autóctones. Algumas delas reforçaram as desigualdades, outras as minimizaram ou mesmo as subverteram. Os resultados dessa interdiscursividade estão visíveis até mesmo nos rituais contemporâneos (Figs. 7 e 8) de devoção às imagens sacras cristãs na Índia. 

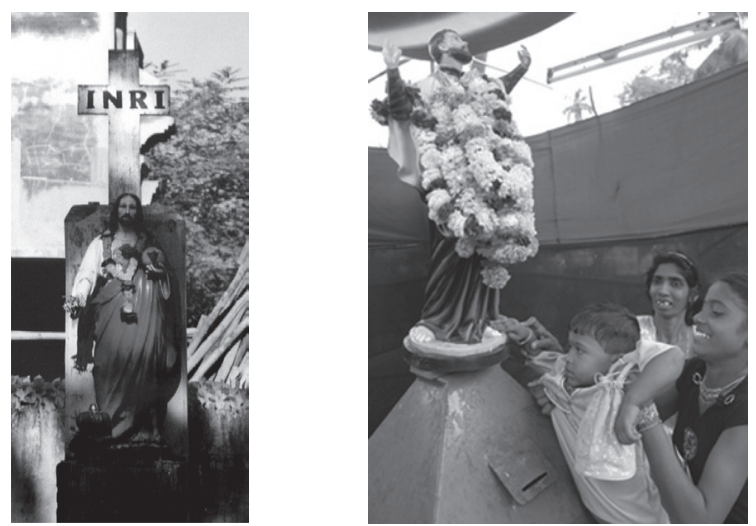

Figuras 7 e 8 Imagens de Jesus e de São Francisco Xavier em Maharashtra, Goa, com guirlandas de flores típicas da adoração dedicada às divindades hindus. A criança toca o pé do santo de modo semelhante ao realizado nos templos hindus

(Fonte: ALDROVANDI 2001-2).

\section{Referências Bibliográficas}

ALDROVANDI, Cibele E. V. A imagética pretérita: perspectivas teóricas da Arqueologia da Imagem. Revista do Museu de Arqueologia e Etnologia. Universidade de São Paulo, São Paulo, n. 19, p. 39-61, 2009.

; HIRATA, Elaine. Buddhism, Pax Kushana and Greco-Roman motifs: pattern and purpose in Gandharan iconography. Antiquity. York, UK, n. 79, p. 306315, 2005.

ANDRADE, Amélia Aguiar. Novos espaços, antigas estratégias: o enquadramento dos espaços orientais. In: CNCDP. Os espaços de um Império. Lisboa, p. 35-45, 1999.

AXELROD, Paul; FUERCH, Michele. Flight of the Deities: Hindu Resistance in Portuguese Goa. Modern Asian Studies. Cambridge, n. 30 (2), p. 387-421, 1996.

. Portuguese Orientalism and the Making of the Village Communities of Goa. Ethnohistory. Durham, North Carolina, n. 45 (3), p. 439-476, 1998.

BADEN-POWELL, Baden Henry. The Villages of Goa in the Early Sixteenth Century. Journal of the Royal Asiatic Society of Great Britain and Ireland. Londres, p. 261291, 1900.

BOXER, Charles R. O império marítimo português 1415-1825. São Paulo: Cia. das Letras (1969) 2002.

BROWN, Leslie. The Indian Christians of St. Thomas. An Account of the Ancient Syrian Church of Malabar. Cambridge: Cambridge University Press, 1982. 
DA CUNHA, Gerson. Notes on the Antiquities of Chaul and Bassein. Bombay: Thacker, Vining \& Co., 1876.

. Shri Sabyadri Khanda Skhanda Purana. Bombay: Thacker, Vining \& Company, 1877.

EUSÉBIO, Fátima. Subsídios para o estudo do intercâmbio de formas na arte indo-portuguesa: o caso específico da arte da talha. Máthesis. Viseu, Portugal, n. 12, p. 57-71, 2003. . A apropriação cristã da iconografia greco-latina: o tema do Bom Pastor. Máthesis. Viseu, Portugal, n. 14, p. 9-28, 2005.

FOUCAULT, M. A arqueologia do saber. Rio de Janeiro: Forense (2008), 1969.

GOGTE, Vishwas D.; ALDROVANDI, Cibele. E. V. A Simylla do périplo do Mar Eritreu: escavação arqueológica do antigo sítio portuário de Chaul na costa oeste de Maharastra - Índia. Revista do Museu de Arqueologia e Etnologia. Universidade de São Paulo, São Paulo, n. 15/16, p. 247-269, 2006.

IRWIN, John. Reflections on Indo-Portuguese Art. Burlington Magazine, London, n. 633, p. 386-388, 1955.

KURTHA, Aziz. Francis Newton Souza: Bridging Western and Indian Modern Art. Ahmedabad: Mapin Publishing Pvt. Ltd., 2006.

LEFÉBVRE, Henri. The Production of Space. Oxford: Blackwell, 1991.

MULLINS, Edwin. Francis Newton Souza. Londres: Anthony Blond Ltd., 1962.

REGO, Antonio da Silva. História das missões do padroado português do Oriente - Índia. Lisboa: Agência Geral das Colônias, 1949.

ROBERTSON, John M. Pagan Christs. Londres: Watts \& Co., 1911.

SALGADO, Javier S. A colecção numismática do Millenium BCP. Revista Artes \& Leilōes. Lisboa, n. 16, mar., 2009.

SANTOS, Boaventura de S. Between Prospero and Caliban: Colonialism, Postcolonialism, and Inter-Identityç. Luso-Brazilian Review. Special Issue: Portuguese Cultural Studies, 39 (2), p. 9-43, 2002.

SUBRAHMANYAM, Sanjay. The Career and Legend of Vasco da Gama. Nova Iorque: Cambridge University Press, 1997.

. Holding the World in Balance: The Connected Histories of the Iberian Overseas Empires, 1500-1640. American Historical Review. Chicago, n. 112 (5): 1359-1385, 2007.

TÁVORA, Bernardo Ferrão de Tavares e. A imaginária luso-oriental. Lisboa: Imprensa Nacional, Casa da Moeda, 1983.

TEIXEIRA, Manuel C. Portuguese Colonial Settlements of the $15^{\text {th }}-18^{\text {th }}$ Centuries. In: C. COAQUERY-VIDROVITCH, O. GOERG (Org.). La ville européenne outre mers: un modèle conquérant? (Xve-XXe siècles). Paris: Harmattan, 1996, p. 15-26.

TRIGGER, Bruce G. Monumental architecture: a thermodynamic explanation of symbolic behavior. World Archaeology. London, n. 22 (2), p. 119-32, 1990.

Recebido em 12/02/2011 e aprovado em 03/04/2011. 